\title{
USING TAGUCHI APPROACH FOR INVESTIGATING MECHANICAL PROPERTIES OF RECYCLED CARBON FIBRE REINFORCED THERMOPLASTICS FOR INJECTION MOULDING APPLICATIONS
}

\author{
Syairah Zainudin, Norshah Aizat Shuaib, Nur'ain Wahidah Ya Omar, \\ Azwan Iskandar Azmi
}

Faculty of Mechanical Engineering Technology, Universiti Malaysia Perlis, Kampus Alam Pauh Putra, 02600 Arau Perlis, Malaysia

Corresponding author: Norshah Aizat Shuaib, norshahaizat@unimap.edu.my

\begin{abstract}
Demand for carbon fibre reinforced plastic (CFRP) increases due to its popular demand in sectors such as automotive and aerospace. This leads to high volume of manufacturing and end of life CFRP waste. The challenge is to recycle the heterogenous waste and utilise the recycled carbon fibre $(\mathrm{rCF})$ in potential applications, including the injection moulding process. However, the effect of processing parameters such as type of new thermoplastics, filler weight loading and particle size on product mechanical properties is not well understood. This study carried out experimental trials based on L4 Taguchi orthogonal design. It is found that the mechanical and physical properties significantly depend on the selected parameters. Optimisation of the parameters should depend on final application of the product. This study highlights potential use of $\mathrm{rCF}$ in reinforcing pure thermoplastics, as well as an alternative material to virgin carbon fibre $(\mathrm{CF})$.
\end{abstract}

Key words: composite, injection moulding, recycling, thermoplastics, Taguchi approach, recycled carbon fibre

\section{INTRODUCTION}

The carbon fibre $(\mathrm{CF})$ usage is growing since it is commercialised in aerospace and automotive applications and continues to grow year by year. Meng et al (2018a) reported that global carbon fibre reinforced plastic (CFRP) production was predicted to be more than 140,000 tonnes per year in 2020 .

Growing of CF demand leads to the increase of waste from manufacturing processes. This necessitates the urge for composite recycling. The categories of composite recycling methods can be divided into several categories such as chemical, thermal and mechanical (Shuaib and Mativenga, 2015). The composite-shaped dust generated from this recycling can be used as filler and reinforcement. Waste produced by cut off, production and end of life can be further processed into new products like yarns, nonwovens and patches. Recycled carbon fibre (rCF) can be used as filler in thermoplastic composite which act to increase the properties of new product. The milled recycled carbon fibre ( $\mathrm{rCF}$ ) can be also incorporated in injection moulded components.

Wölling et al (2017) reported that filler or short fibre used for injection moulding processes usually has particle size below $1 \mathrm{~mm}$. Fibre less than $10 \mathrm{~mm}$ in size can be applied in wet laid nonwoven production while long fibres can be used for yarn-building processes and dry laid nonwovens. Holmes (2018) reported that Sanko Gosei UK Ltd replaced glass fibre polypropylene compound with milled rCF with fibre volume of $30 \%$. As a result, the headlamp rigidity increased, and the weight reduced by as much of eight percent.

According to Uhlmann and Meier (2017), CFRP milling dust has been used as reinforcement in polypropylene. The rigidity and tensile strength of the product improved. CFRP from milling dust can be recognised as supplement act as a filler. As stated by Meng et al (2018b), around 15\% cost reduction can be achieved by recovering CF from CFRP waste compared to virgin CF production. Recycled CFRP is one of the lightest alternative replacements and can improve financial performance. However, the effect of particle size and fibre volume is rarely considered in literature. Type of plastic which is suitable for $\mathrm{rCF}$ reinforcement is not clearly highlighted. Relationships between these factors are not thoroughly studied. Therefore, a multi-objective optimisation study is required in determining best combination of parameters for optimum mechanical properties.

This study focuses on milled rCF waste recovered from a pyrolysis process. Two types of thermoplastics were selected as the matrix to be reinforced with the rCF waste, which were low density polyethylene (LDPE) and acrylonitrile butadiene styrene (ABS). Parameters considered were the filler size and weight loading. The experimental trials were planned based on L4 orthogonal array Taguchi method. Taguchi system is in a table form where this system can reduce 
the number of samples that need to be submitted without reducing the information that needs to be studied. Among the advantages that can be gained from this method is to save time and resources, while evaluating every single important factors. Findings of this study focus on mechanical properties of the injection moulded composites from the aspects of tensile strength, tensile modulus, tensile failure strain, flexural strength, flexural modulus, flexural failure strain, water absorption and morphology of tensile fractured surface. This investigation introduces an alternative material, which is cheaper compared to cost of virgin $\mathrm{CF}$. The finding can provide an informed decision for the manufacturers regarding the best strategy in using milled $\mathrm{rCF}$ waste for optimum mechanical properties. From here, commercial value of the $\mathrm{rCF}$ waste can be greatly appreciated.

\section{RESEARCH METHODOLODY}

Figure 1 shows a summary of the methodology in this study. The procedure can be classified into two stages which are the sample preparation stage and the testing stage.

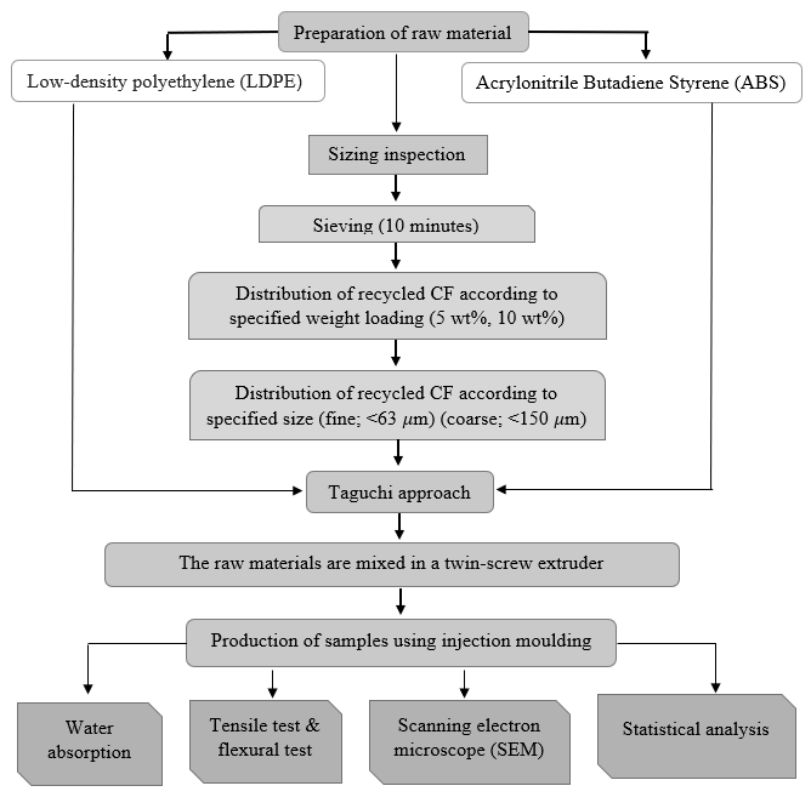

Fig. 1. Research methodology

The milled rCF was in a powdered form and was supplied by ELG Carbon Fibre Ltd, United Kingdom with size range $63 \mu \mathrm{m}$ to $212 \mu \mathrm{m}$. The $\mathrm{rCF}$ was obtained from a pyrolysis recycling process. The $\mathrm{rCF}$ acted as the reinforcement in the LDPE and ABS thermoplastics. The LDPE and ABS pellets used were purchased from Lotte Chemical Titan (M) Sdn Bhd and Sheng Foong Plastics Sdn Bhd, respectively. The rCF had been sieved several times and each trial was carried out for 10 minutes to classify the filler into coarse and fine particles. The sieving process was done using a sieve shaker machine with sieve sizes of $212 \mu \mathrm{m}, 150 \mu \mathrm{m}, 75 \mu \mathrm{m}$ and $63 \mu \mathrm{m}$. Particle size between $63 \mu \mathrm{m}$ to $150 \mu \mathrm{m}$ was classified as the coarse particle and the rCF less than $63 \mu \mathrm{m}$ was considered as the fine particle.

In order to reduce the number of samples required, Taguchi approach for experimental design was applied. This method uses a unique design of orthogonal arrays to analyse the entire parameter space with small number of experiments. Taguchi L4 orthogonal array for three factors and two levels was applied to design experimental plan as shown in Table 1. Using Analysis of Variance (ANOVA), the effect of input parameters on type of thermoplastics, particle size and weight loading factor was studied at 95\% confidence level. Minitab software was used for the statistical analysis of the result. The factor with the highest percentage of the contribution was ranked the highest in terms of the relative importance among all the factors and has a major contribution in the overall response. Mean effect plot and contour plot were used in explaining the effect of each input parameter and relationship between the variables.

Table 1. Experimental trials based on L4 Taguchi orthogonal array design

\begin{tabular}{|c|c|c|c|}
\hline Product & $\begin{array}{c}\text { Type of } \\
\text { thermoplastic }\end{array}$ & $\begin{array}{c}\text { rCF particle } \\
\text { size }(\boldsymbol{\mu m})\end{array}$ & $\begin{array}{c}\text { rCF weight } \\
\text { loading }(\mathbf{w t} \%)\end{array}$ \\
\hline A & ABS & $63($ Fine $)$ & 5 \\
\hline B & ABS & $150($ Coarse $)$ & 10 \\
\hline C & LDPE & $63($ Fine $)$ & 10 \\
\hline D & LDPE & 150 (Coarse) & 5 \\
\hline
\end{tabular}

The products were mixed individually using LabTech twin-screw extruder with a screw speed of $160 \mathrm{rpm}, 20$ rpm feeding screw speed and temperature of $210{ }^{\circ} \mathrm{C}$. The machine was supplied by Labtech Engineering Company Ltd from Thailand. The process was to ensure that the thermoplastic and rCF were mixed homogeneously. The extruded compound was then cooled and granulated into pellets by a pelletiser. The pellets were used to produce dog bone $(164 \mathrm{~mm} \times 13$ $\mathrm{mm} \times 3 \mathrm{~mm})$ and block samples $(120 \mathrm{~mm} \times 13 \mathrm{~mm} \times 3$ $\mathrm{mm}$ ) using BOY $35 \mathrm{E}$ injection moulding machine at a temperature of $180{ }^{\circ} \mathrm{C}$. The machine was manufactured by Dr. Boy GmbH \& Co. KG in Germany.

The tensile tests were carried out using the Shimadzu Universal Testing Machine AG-XD plus according to ASTM D638. The gauge length was set to $50 \mathrm{~mm}$. Testing speed used was $5 \mathrm{~mm} / \mathrm{min}$ with $115 \mathrm{~mm}$ distance between the two grips. The flexural tests were performed based on ASTM D790 with $5 \mathrm{~mm} / \mathrm{min}$ speed.

For water absorption test, a sample with a dimension of $10 \mathrm{~mm}$ in length and $10 \mathrm{~mm}$ in width was used for each product. The test was carried out according to ASTM D570. Before the samples were immersed in a distilled water, the samples were weighed using a 
weight balance. The samples were placed in a container and immersed in the distilled water at $26^{\circ} \mathrm{C}$ average room temperature for two weeks. Then, samples were removed at the designated time and the samples were wiped using a dry cloth and weighed. The percentage difference between the final and the initial weight was taken as the water absorptivity.

The tensile fracture for each product was observed by using a Scanning Electron Microscope (SEM). The fracture surfaces were mounted on a platinum stub to undergo sputtering platinum coating. The coating was to make sure the samples act as a conductor material which to avoid charging during analysis. The samples were coated with $20 \mathrm{~nm}$ thin layer of platinum by using Q150R plus rotary pumped coater. For SEM analysis, the samples were arranged on a holder in Hitachi TM3000 machine. The magnification used for observation was 500x.

\section{RESULTS AND DISCUSSIONS}

Table 2 shows mechanical and physical properties of pure ABS and LDPE, which were used as control products in this study. Table 3 presents the percentage change of each output variable in comparison with the control products. This is to ensure a fair comparison since ABS product is known to have greater mechanical properties compared to LDPE product. Positive value indicates that the $\mathrm{rCF}$ reinforcement provides an improvement in terms of the tensile and flexural properties. For water absorptivity, negative value is desirable to ensure the thermoplastic products are water resistance.

Table 4 presents the F-value and p-value for each parameter and output variable. The effect of factor is interpreted to be significant when the p-value is less than 0.05 . The F-value represents variability of the distribution. Low F-value means low variability and the sample has narrow data distribution.

The tensile strength increases with addition of rCF content from $0 \mathrm{wt} \%$ to $5 \mathrm{wt} \%$ for both particle sizes. The strength of a composite changes due to microscopic damage because of interfacial debonding cracked or broken resins. The result agrees with a finding from a study by Qiu \& Wei (2016). The study found that $5 \mathrm{wt} \%$ increased strength of $\mathrm{CF}$ composites fabricated using fused deposition modelling, but further addition of filler up to $10 \%$ can deteriorate the strength.

Filler size also plays an important role in influencing the tensile strength. Samples with the small particle size had higher tensile strength. This due to interference of filler mobility or deformability. Coarse particle has low tensile strength because bigger particle lead to stress raisers in a composite.

Modulus of elasticities for ABS and LDPE show the same pattern which increases linearly with $\mathrm{rCF}$ content. The result also shows that the rCF reinforcement notably improves modulus properties of the products. This behaviour obeys the rule of mixture. Low modulus and strength are probably due to low efficiency of reinforcement of short fibre.

In general, product with high filler content has higher modulus compared to the pure plastic product. This is on account of the dispersed particles make the crack propagation path longer.

Comparing filler weight loading and size, it can be said that the particle size has greater influence in flexural strength of the products. Smaller particle size of filler provides greater strength compared to the coarse size. This can be due to smaller particle size filler has larger surface area which make the particles difficult to slide from the slab when the sample bends. Besides, the small particles can fill the empty space inside the sample. Large surface area means higher total area for deformation stress.

Table 2. Mechanical and physical properties of pure ABS and LDPE products

\begin{tabular}{|c|c|c|c|c|c|c|c|}
\hline Product & $\begin{array}{c}\text { Tensile } \\
\text { strength } \\
(\mathbf{M P a})\end{array}$ & $\begin{array}{c}\text { Tensile } \\
\text { modulus } \\
\mathbf{( M P a )}\end{array}$ & $\begin{array}{c}\text { Tensile } \\
\text { failure strain } \\
(\mathbf{\%})\end{array}$ & $\begin{array}{c}\text { Flexural } \\
\text { strength } \\
(\mathbf{M P a})\end{array}$ & $\begin{array}{c}\text { Flexural } \\
\text { modulus } \\
(\mathbf{M P a})\end{array}$ & $\begin{array}{c}\text { Flexural } \\
\text { failure strain } \\
(\boldsymbol{\%})\end{array}$ & $\begin{array}{c}\text { Water } \\
\text { absorptivity } \\
(\boldsymbol{\%})\end{array}$ \\
\hline ABS & 44.53 & 1995.06 & 3.44 & 81.63 & 3250.22 & 3.31 & 2.77 \\
\hline LDPE & 8.51 & 142.15 & 78.42 & 5.85 & 10.57 & 4.86 & 2.54 \\
\hline
\end{tabular}

Table 3. Changes of mechanical properties of rCF reinforced thermoplastics compared to pure thermoplastics product

\begin{tabular}{|c|c|c|c|c|c|c|c|}
\hline Product & $\begin{array}{c}\text { Tensile } \\
\text { strength }\end{array}$ & $\begin{array}{c}\text { Tensile } \\
\text { modulus }\end{array}$ & $\begin{array}{c}\text { Tensile } \\
\text { failure strain }\end{array}$ & $\begin{array}{c}\text { Flexural } \\
\text { strength }\end{array}$ & $\begin{array}{c}\text { Flexural } \\
\text { modulus }\end{array}$ & $\begin{array}{c}\text { Flexural } \\
\text { failure strain }\end{array}$ & $\begin{array}{c}\text { Water } \\
\text { absorptivity }\end{array}$ \\
\hline Product A & $3.18 \pm 1.16$ & $44.67 \pm 2.73$ & $-14.34 \pm 4.36$ & $7.26 \pm$ & 23.27 & -2.41 & $-56.92 \pm$ \\
& & & & 0.68 & \pm 3.00 & \pm 4.97 & 5.43 \\
\hline Product B & $-5.58 \pm 5.03$ & $77.44 \pm$ & $-27.52 \pm 11.92$ & $4.29 \pm$ & 31.10 & $-4.43 \pm 1.22$ & $-14.20 \pm$ \\
& & 14.67 & & 0.74 & \pm 1.93 & 37.74 \\
\hline Product C & $6.19 \pm 0.87$ & $50.55 \pm 2.12$ & $-14.99 \pm 0.07$ & $48.31 \pm$ & 40.13 & $3.09 \pm 3.07$ & $-3.41 \pm$ \\
& & & & 4.39 & \pm 16.85 & & 18.32 \\
\hline Product D & $23.70 \pm 0.54$ & $129.55 \pm$ & $-50.75 \pm 5.92$ & $96.75 \pm$ & $77.92 \pm$ & $0.27 \pm 2.72$ & $-56.17 \pm$ \\
& & 18.62 & & 8.15 & 14.33 & & 9.62 \\
\hline
\end{tabular}


Table 4. F-value, p-value and rank with result interpretation for all parameters and output variables

\begin{tabular}{|c|c|c|c|c|c|c|c|c|}
\hline \multirow{2}{*}{\multicolumn{2}{|c|}{ Parameter }} & \multicolumn{7}{|c|}{ F-value, p-value and rank with result interpretation } \\
\hline & & \multirow{2}{*}{$\begin{array}{c}\begin{array}{c}\text { Tensile } \\
\text { strength }\end{array} \\
12.40\end{array}$} & \multirow{2}{*}{$\begin{array}{c}\begin{array}{c}\text { Tensile } \\
\text { modulus }\end{array} \\
2.08\end{array}$} & \multirow{2}{*}{$\begin{array}{c}\begin{array}{c}\text { Tensile } \\
\text { failure strain }\end{array} \\
1.66\end{array}$} & \multirow{2}{*}{$\begin{array}{c}\begin{array}{c}\text { Flexural } \\
\text { strength }\end{array} \\
36.08\end{array}$} & \multirow{2}{*}{$\begin{array}{c}\begin{array}{c}\text { Flexural } \\
\text { modulus }\end{array} \\
9.39\end{array}$} & \multirow{2}{*}{$\begin{array}{c}\begin{array}{c}\text { Flexural } \\
\text { failure } \\
\text { strain }\end{array} \\
7.51\end{array}$} & \multirow{2}{*}{$\begin{array}{c}\begin{array}{c}\text { Water } \\
\text { absorptivity }\end{array} \\
0.09\end{array}$} \\
\hline \multirow{3}{*}{$\begin{array}{c}\text { Type of } \\
\text { thermoplastic }\end{array}$} & $\begin{array}{c}\text { F- } \\
\text { value }\end{array}$ & & & & & & & \\
\hline & $\begin{array}{c}\text { p- } \\
\text { value }\end{array}$ & $0.006(\mathrm{~S})$ & $0.180(\mathrm{NS})$ & $0.226(\mathrm{NS})$ & $0.000(\mathrm{~S})$ & $0.012(\mathrm{~S})$ & $0.021(\mathrm{~S})$ & $0.766(\mathrm{NS})$ \\
\hline & Rank & 1 & 3 & 2 & 1 & 1 & 1 & 3 \\
\hline \multirow{3}{*}{$\begin{array}{l}\text { Weight } \\
\text { loading }\end{array}$} & $\begin{array}{c}\text { F- } \\
\text { value }\end{array}$ & 0.42 & 17.76 & 14.93 & 1.00 & 3.31 & 1.06 & 0.07 \\
\hline & $\begin{array}{c}\text { p- } \\
\text { value }\end{array}$ & $\begin{array}{l}0.530 \\
(\mathrm{NS})\end{array}$ & $0.002(\mathrm{~S})$ & $0.003(\mathrm{~S})$ & 0.341 (NS) & $\begin{array}{c}0.099 \\
(\mathrm{NS})\end{array}$ & $0.327(\mathrm{NS})$ & $0.796(\mathrm{NS})$ \\
\hline & Rank & 3 & 1 & 1 & 2 & 2 & 2 & 2 \\
\hline \multirow{3}{*}{ Filler size } & $\begin{array}{c}\text { F- } \\
\text { value }\end{array}$ & 5.79 & 1.23 & 1.46 & 1.31 & 1.20 & 0.03 & 17.36 \\
\hline & $\begin{array}{c}\text { p- } \\
\text { value }\end{array}$ & $0.037(\mathrm{~S})$ & $0.294(\mathrm{NS})$ & $0.254(\mathrm{NS})$ & 0.279 (NS) & $\begin{array}{l}0.299 \\
(\mathrm{NS})\end{array}$ & $0.874(\mathrm{NS})$ & $0.002(\mathrm{~S})$ \\
\hline & Rank & 2 & 2 & 3 & 3 & 3 & 3 & 1 \\
\hline
\end{tabular}

S: Significant, NS: Not significant

Figure 2 shows SEM images of the tensile fractured samples. Fibre pull out can still be seen with residual resin still attached on the fibre surface. This indicates the bonding between the surface of thermoplastic matrix and $\mathrm{rCF}$ filler is good enough, which supported by positive values of changes in Table 3 . Figure 2 (a) and Figure 2 (c) indicates brittle and ductile behaviour respectively, which can be related to the strain trait of ABS and LDPE polymers.

Pure ABS and LDPE products have high failure strain. With the addition of $\mathrm{rCF}$, the elongation at break also increases and led to negative value of changes in failure strains. The addition of fibre content as filler, can reduce failure strain of the material. This conclusion is based on the fibre matrixinterface and its adhesion. Besides, the $\mathrm{CF}$ is more brittle than plastics. Therefore, the addition of CF can reduce the ductile nature of the pure plastic.

Good performances are shown for the water absorptivity, represented by the negative values. The addition of $\mathrm{rCF}$ prevents the product from absorbing water. CF has hydrophobic nature, which causes water molecules difficult to enter the sample. The sample with coarse particle size absorbs more water. This due to more pores in the sample, which the water could enter the sample through capillary action. It can be concluded that products reinforced with $\mathrm{rCF}$ have a potential to be used in a moist condition.

From Table 4, statistically significance for each parameter varies across all variables. Type of thermoplastic has a significant influence on the tensile strength, the flexural strength, and the flexural modulus. The tensile modulus and the tensile strain depend highly on the weight loading, which represented by the low p- values. Filler size only influences the tensile strength and the water absorptivity.

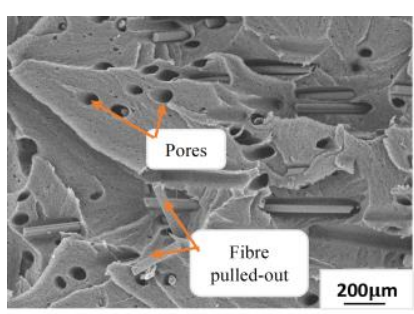

a)

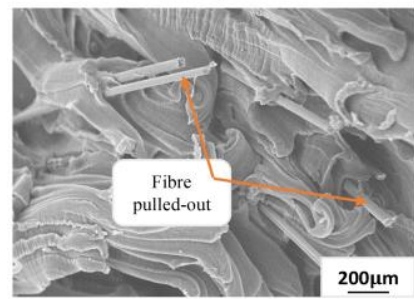

c)

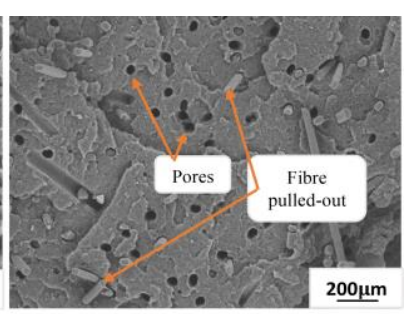

b)

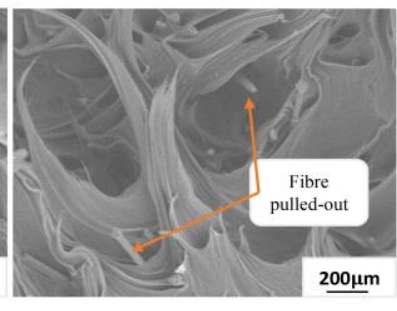

d)
Fig. 2. SEM images of tensile fracture surface of a) Product A (ABS with 5 wt $\%$ fine size) b) Product B (ABS with $10 \mathrm{wt} \%$ coarse size) c) Product C (LDPE with $5 \mathrm{wt} \%$ coarse size) d) Product D (LDPE with $10 \mathrm{wt} \%$ fine size)

Main effect plot of mean between each factor and output variables are illustrated in Figure 3. Slope of the line represents degree of influence of each factor for the variable. The type of thermoplastic shows great influence on the flexural properties, as presented in Figure 3(d), Figure 3(e) and Figure 3(f). The rCF has better reinforcement effect in the flexural properties of the LDPE products. For the water absorptivity, only the filler size has a significant effect, where products with finer particle size can contribute to the water resistivity trait. 


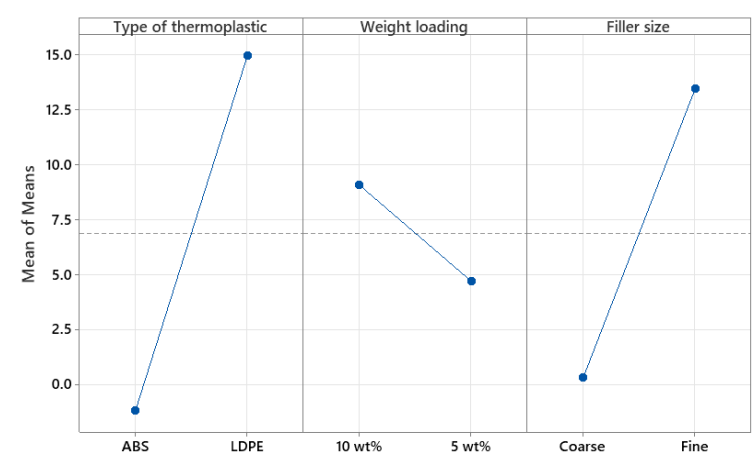

a)

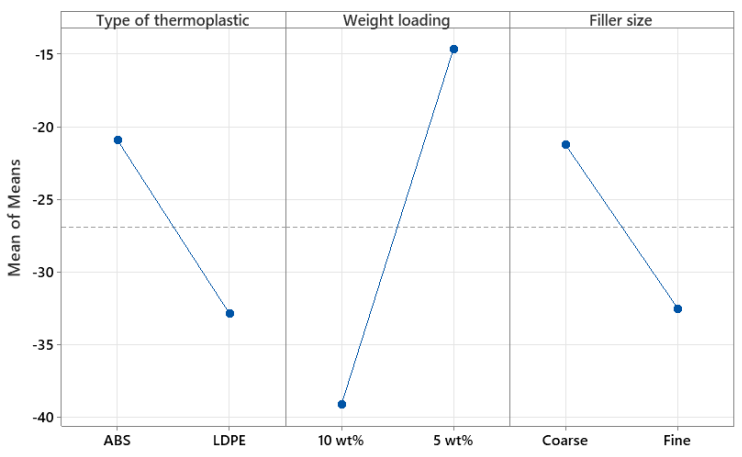

c)

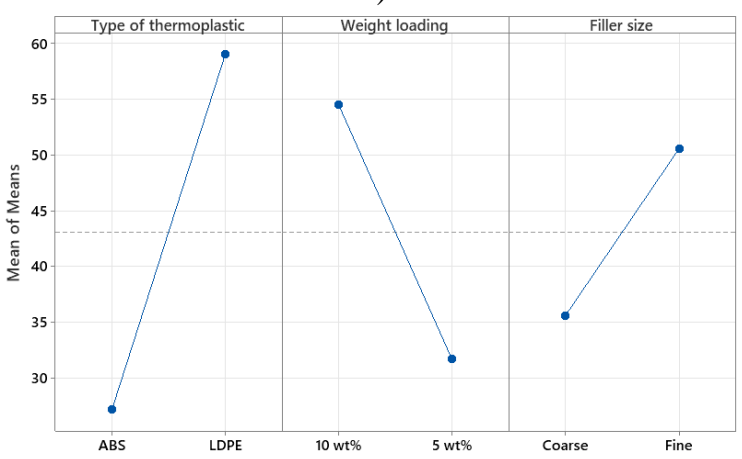

e)

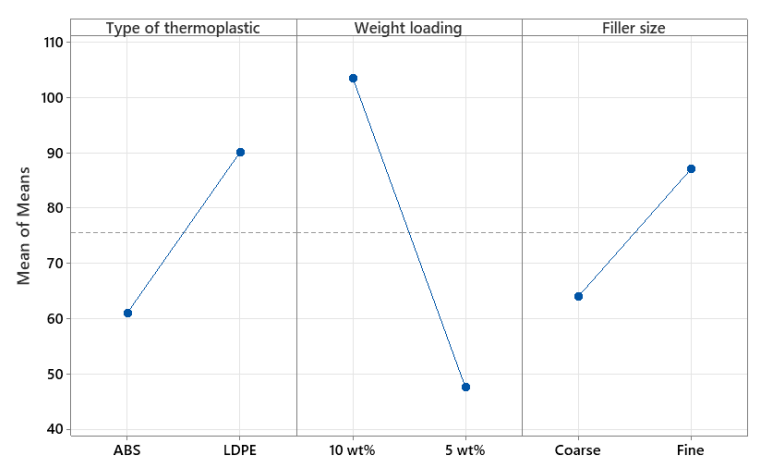

b)

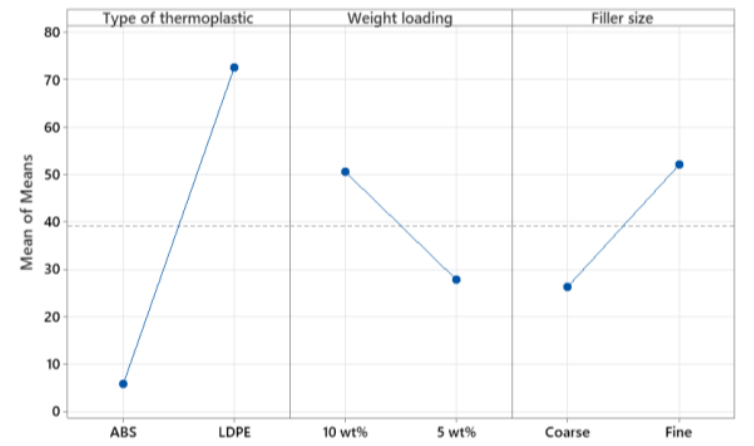

d)

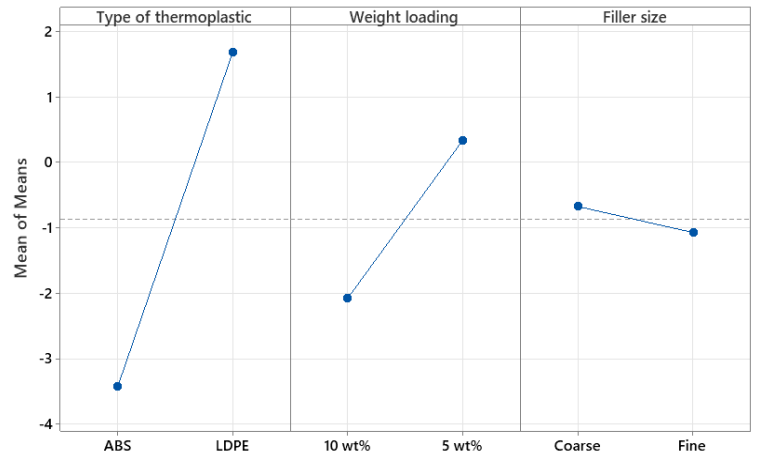

f)

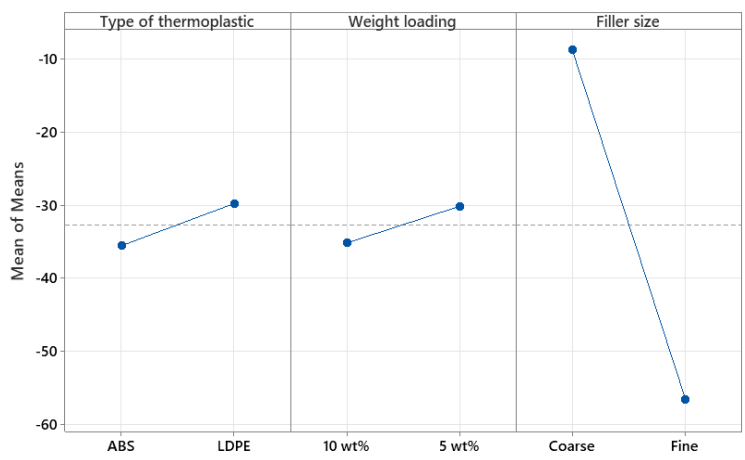

g)

Fig. 3 Main effect plots for a) tensile strength, b) tensile modulus, c) tensile failure strain, d) flexural strength, e) flexural modulus, f) flexural failure strain and g) water absorption

Multi-objective optimisation analysis for selected outputs is presented in contour plots in Figure 4 and Figure 5. The plots show relationship between selected output variables which allow area of optimum performance to be predicted and identified. In Figure 4, the plot considers the changes of the tensile strength, the flexural strength and the tensile modulus. Area A is where maximum positive changes of all variables. The parameters dedicated to Area A are LDPE for type of thermoplastic, $10 \mathrm{wt} \%$ loading and $63 \mu \mathrm{m}$ or fine filler size. Area B indicates least desirable performance with minimum positive changes for the selected outputs. 


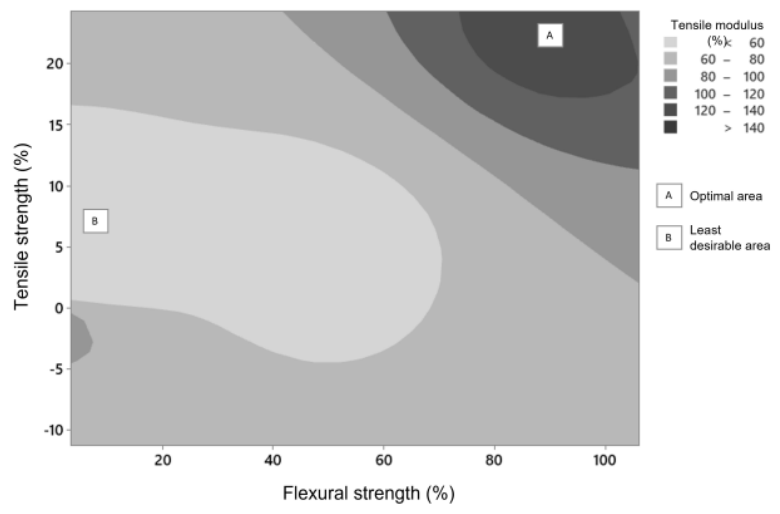

Fig. 4. Contour plot of tensile strength versus flexural strength versus tensile modulus

Figure 5 shows a contour plot, illustrating relationship between the tensile failure strain, the flexural failure strain and the flexural strength. There is no area with optimum performance of all outputs. Area $\mathrm{C}$ is where two output i.e., flexural strength and flexural failure strain can be optimised, but with an expense of the third which is the tensile failure strain.

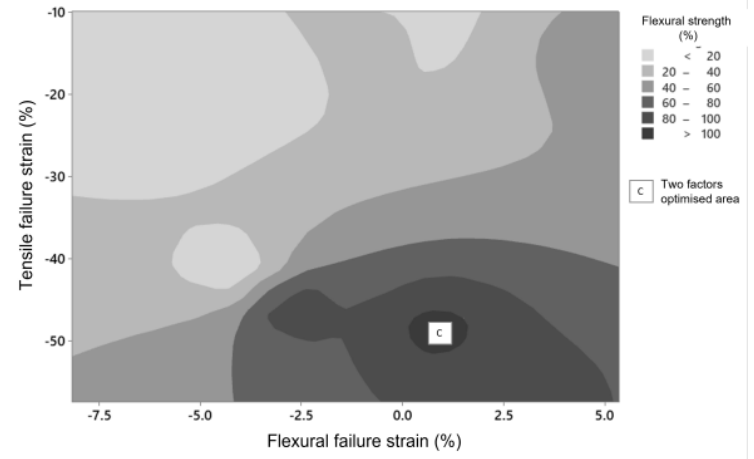

Fig. 5. Contour plot of tensile failure strain versus flexural failure strain versus flexural strength

\section{CONCLUSIONS}

This study set out to investigate effect of parameters in fabricating $\mathrm{rCF}$ reinforced thermoplastics on mechanical properties of the products. The most obvious finding in this study is that type of thermoplastic, filler weight loading, and particle size have significant influence on the changes of the properties compared to the control or pure thermoplastic products. It is challenging to determine the best parameters as each property is influenced by different factors. Therefore, selection of the parameters should be done based on final application of the rCF reinforced product. For instance, a product which exposes to prolonged bending stress should emphasise on using LDPE instead of ABS, $10 \mathrm{wt} \%$ loading and coarse particle.

This study also highlights the usage of $\mathrm{rCF}$ in potential applications which can be a cheaper and greener alternative material to virgin CF. For future work, full factorial design experimental trials considering each factor individually should be carried out. This preliminary work can also be extended to cover other processing parameters such as mould temperature, injection pressure and cycle time, as well as surface modification for the rCF.

\section{ACKNOWLEDGEMENT}

The author would like to acknowledge the financial support from the Fundamental Research Grant Scheme (FRGS) under a grant number of FRGS/1/2018/TK03/UNIMAP/02/15 from the Ministry of Higher Education Malaysia.

\section{REFERENCES}

1. Holmes, M. (2018). Recycled carbon fiber composites become a reality. Reinforced Plastics, 62 $1-6$.

2. Meng, F., Olivetti, E. A,. Zhao, Y., Chang, J.C., \& Pickering, S. J., McKechnie, J., (2018a). Comparing life cycle energy and global warming potential of carbon fiber composite recycling technologies and waste management options. ACS Sustain. Chem Eng 6, 9854-65.

3. Meng, F., Mckechnie, J., \& Pickering, S. J. (2018b). An assessment of financial viability of recycled carbon fibre in automotive applications. Compos. Part. A-Appl. S., 109, 207-220.

4. Qiu, J., \& Wei, J. (2016). Additive manufacturing of carbon fiber reinforced thermoplastic composites using fused deposition modeling. Compos. Part. BEng., 80, 369-378.

5. Shuaib, N. A. \& Mativenga, P. T., (2015). Energy intensity and quality of recyclate in composite recycling. Proceedings of the ASME 2015 International Manufacturing Science and Engineering Conference. Volume 2: Materials; Biomanufacturing; Properties, Applications and Systems; Sustainable Manufacturing. ASME. Charlotte, North Carolina.

6. Uhlmann, E., \& Meier, P. (2017). Carbon fibre recycling from milling dust for the application in short fibre reinforced thermoplastics. Proc. CIRP., 66, 277-282.

7. Wölling, J., Schmieg, M., Manis, F., \& Drechsler, K. (2017). Nonwovens from recycled carbon fibres comparison of processing technologies. Proc. CIRP., 66, 271-276.

Received: September 12, 2021 / Accepted: December 15, 2021 / Paper available online: December 20, 2021 (C) International Journal of Modern Manufacturing Technologies. 